colours of some Alpine Coleoptera are brighter than those of the warmer plains, and that the species of small islands often show a tendency to melanism, are at present simply inexplicable, but, as far as I can see, do not tell for or against either theory. It would certainly be a strong case against the present view if any animal could be named which became white in winter and was not an inhabitant of a country subject to cold winters. As far as my knowledge extends no such species exists. The light colour of desert mammals is most probably due to predatory advantage - - the melanism of desert insects mentioned by Sig. Camerano is, I must confess, a new fact to me, and not at all in accordance with my own limited experience. The strongest objection raised by Sig. Camerano is, perhaps, contained in the statement that in the birds of the Antarctic region black is much more prevalent than in those of the Arctic regions. It is unfortunate, however, that the writer adduces in illustration such countries as Australia and New Zealand, which certainly cannot be considered within the Antarctic region.

In conclusion I should like to emphasize that the theory of climatic protection is not, as Mr. Wallace appears to believe, opposed to the theory of adaptation. If my first letter gave rise to this impression, I will take the present opportunity of pointing out that the animal kingdom abounds with cases of what our German colleagues happily call "functional change" (Functionszechsel) - that is, the conversion of a character (or function) originally acquired for one purpose to a totally new use. It is thus not at all improbable that a mode of coloration originally acquired as a climatic protection, may afterwards be found to be of adaptive value, so that climatic and natural selection would in such cases work together. I fully concede that many of the Arctic and Alpine species now derive such advantages from their white covering; the question is whether this colouring was originally acquired solely for this purpose, or whether climatic adaptation may not have had an equal or even a greater influence in its production.

R. Meldola

\section{Clifford and Professor Tait}

MAY a "(so-called) Metaphysician"-who has molestly waited to see if some one for whom Prof. Tait could have more respect would anticipate him-venture to remark upon a passage in the review of Clifford's "Exact Sciences" that appeared in NATURE of June II?

Prof. Tait first calls "awkward" and "unnecessarily puzzling 'Clifford's statement that 'if we can fill a box with cubes whose height, length and breadth are all equal to one another, the shape of the box will be itself a cube'; and then, declaring with greater emphasis that it "at first sight seems to be nonsense," he adds :--" Read it, however, thus: "If we can fill with cubes a box whose height, \&c. . . . the shape of the box itself will be a cube,' and the absurdity, suggested by the collocation, disappears."

Now Clifford's statement is not sufficiently guarded, being, as it stands, not true of the cube only; but it surely conveys a real meaning, in a "collocation" of words as plain as possible. It is something (whether much or little) to be told that a cube can be made up of a number of equal cubes; especially in view of the context (p. I6). But does Prof. Tait, with his sentence, tell us anything at all, except that a cube is-a cube; or say even that plainly?

June 22

\section{Unusual Atmospheric Phenomenon}

THE accompanying drawing-a copy of a sketch taken at the time-represents an unusual atmospheric phenomenon witnessed by several friends and myself during a recent visit to Ireland. It occurred on the 6th inst., a bright warm day, with a light breeze blowing from the east. The sky was free from clouds, excepting a few cirrus and cirro-stratus collections on the northern horizon. Engaged at the time in fishing from a boat on one of the Irish loughs, I was conscious of a change in the character of the light reflected from the water and distant objects and looking towards the sun $(f)$, noticed that it was surrounded by an exceedingly brilliant halo $(a b)$ of about $48^{\circ}$ diameter, the contained space $(g h)$ being filled with vapour of 2 dull leaden blue colour, which, by obscuring some of the solar rays, apparently produced the peculiar light effects that first attracted my attention. The time was I. 30 in the afternoon. Calling the attention of my friend, Dr. Simpson, to the pheno- menon, I recorded the accompanying details. The primary linla $(a b)$ consisted of a brilliant, well-defined band of about 8 width, composed of the spectral colours in the usual sequence, the red ring being nearest the sun. The whole band was most vivid, but the northern half the brightest. At about two o'clock I noticed a bulging $(i)$ of the leaden-coloured vapour of the primary halo $(a b)$ to the extent of $6^{\circ}$ or $7^{\circ}$, and in its south-eastern quadrant, and this protrusion, at first only faintly fringed with colour, soon was bounded by a spectral bow (e) at least as vivid as the brightest portion of the primary halo. The adjacent portion of $a b$, whether by comparison with $e$ or whether because partially obscured by the protrusion of the vapour around which $e$ was formed, I cannot be sure, seemed much paler than the rest of $a b$. Simultaneously with the formation of this secondary bow a large white ring, represented in the drawing by $c d$, slowly formed around a centre to the north of the sun, and rapidly assumed a well-defined contour. Its diameter was $72^{\circ}$. Had it been complete it would in its southern portion have passed through the sun, but after cutting the primary halo $(a b)$ at the points ( $m$ and $n$ ),

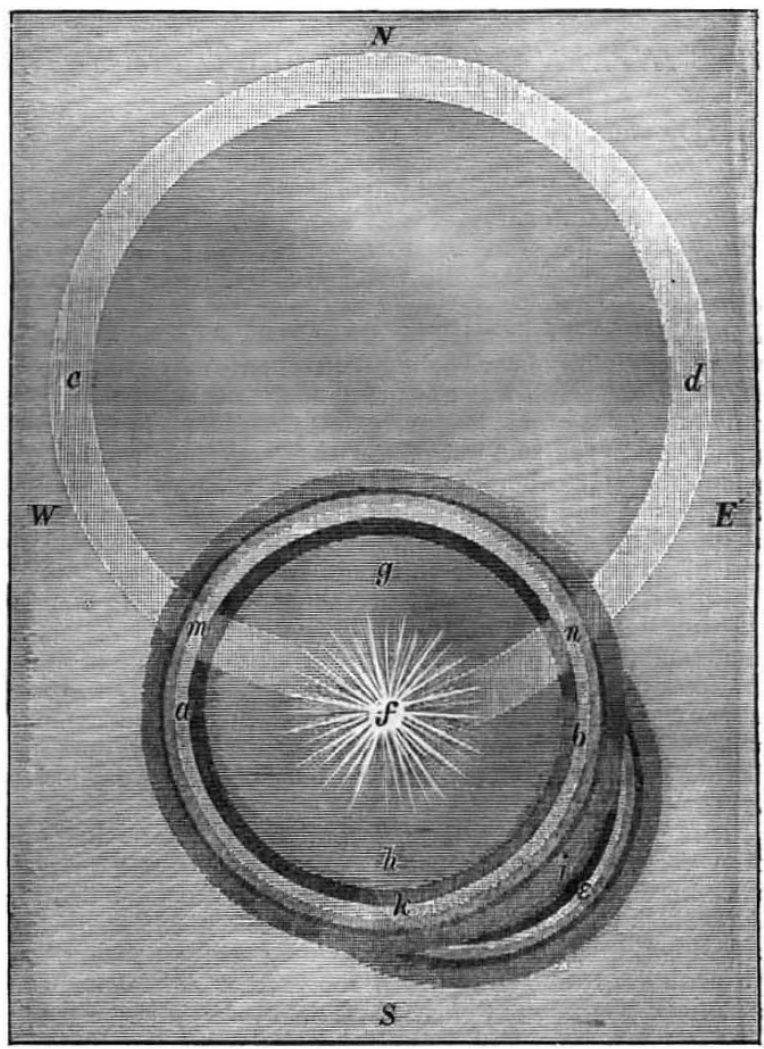

which it rendered more faint, it gradually disappeared before reaching the sun. This latter ring $(c d)$ began to disappéar about a quarter of an hour after 1 first noticed it, its no thwestern portion fading first. I noticed no mock-suns at the points of contact of either of the excentric rings, and was, unfortunately, unprovided with my small pocket polariscope, and therefore unable to ascertain how much of the phenomenon was due to double refraction. The portion $(e)$ may have been thus produced, but it certainly appeared, as drawn, to be a portion of a ring of smaller radius than $(a b)$. The Rev. T. G. Beaumont, who also observed this spectacle, states that he saw the primary halo $(a b)$ gradually start from a much smaller ring around the sun. The accompanying drawing, though rough, is as accurate as compatible with the absence of measuring instruments.

26, King Street, Manchester, June I6

Alex. HODGKINSON

\section{Sky-Glows}

Your correspondent of Clairvaux-sur-Aube says (NATURE, vol. xxxii. p. 147) the sky-glows are again visible in France. I 